\title{
DESENVOLVIMENTO DE COMPOSTOS DE COORDENAÇÃO PARA APLICAÇÃO FOLIAR
}

\author{
Keila C. Marques da Silva ${ }^{1^{*}}$, Ana M. Costa Ferreira ${ }^{{ }^{*}}$ \\ 1 -Instituto de Química, Universidade de São Paulo (USP), São Paulo, SP \\ keila.silva@,compassminerals.com.br
}

\begin{abstract}
Resumo: O desenvolvimento de complexos de metais de transição tem se mostrado de grande valia no manejo de nutrientes na agricultura. Foram desenvolvidos complexos dos metais cobre, manganês, zinco, cobalto e níquel com os complexantes ácido aspártico e ácido glutâmico, que em seguida foram secos em spray dryer para obtenção dos compostos na forma sólida. Suas caracterizações através de solubilidade, $\mathrm{pH}$, densidade, $\mathrm{pH}$ de decomposição, compatibilidade com agrotóxicos e afins e corrosão foram realizadas, obtendo resultados satisfatórios para cada uma das determinações. Os compostos desenvolvidos possuem alta estabilidade sob estresse térmico quando submetidos à envelhecimento acelerado para determinação de tempo de prateleira (shelf-life). Além disso, ao realizar aplicação foliar dos compostos desenvolvidos, os resultados foram igualmente satisfatórios com valores superiores ao controle para cada elemento.
\end{abstract}

Palavras-chave: complexo de metal de transição, ácido aspártico, ácido glutâmico, aplicação foliar.

Abstract:

Development of coordination compounds for foliar application

The development of transition metal complexes has proved to be of great value in the management of nutrients in agriculture. Complexes of the metals copper, manganese, zinc, cobalt and nickel were developed with the complexing agents aspartic acid and glutamic acid, and then dried in a spray dryer to obtain the compounds in solid form. Their characterization by solubility, $\mathrm{pH}$, density, decomposition $\mathrm{pH}$, compatibility with pesticides and corrosion were performed, obtaining satisfactory results for each of the determinations. The developed compounds have high stability under thermal stress when subjected to accelerated aging to determine shelf life. In addition, when performing foliar application of the compounds developed, the results were equally satisfactory with values higher than the control for each element.

Keywords: transition metal complexes, aspartic acid, glutamic acid, foliar application.

\section{Introdução}

A meta do manejo de nutrientes é fornecer um suprimento adequado de todos os nutrientes essenciais para uma cultura durante o período de crescimento. Se a quantidade de qualquer nutriente é limitante em qualquer momento, existe um potencial para perda da produção. Os fertilizantes precisam ser aplicados em todos os tipos de sistemas de produção das culturas com a finalidade de se obter níveis adequados de produtividades que fazem com que os esforços de produção sejam vantajosos. ${ }^{1}$ Atualmente, é aceito que a vida vegetal teve seu início na água. Neste habitat, onde hoje ainda vive a maioria dos vegetais, as plantas tinham à sua disposição todos os fatores necessários. Com a adaptação das plantas fora da água, por meio da evolução, as partes da planta se especializaram e passaram a executar determinadas funções. As raízes se especializaram em fixação e absorção de nutrientes, as folhas em fotossíntese e respiração e o caule em transporte de solutos, ligando as raízes às folhas. Entretanto, as partes aéreas não perderam a capacidade de absorver nutrientes. ${ }^{2}$ Fertilizantes foliares são, de longe, o mais efetivo sistema para aplicar micronutrientes ou pequenas quantidades de nutrientes como suplementos dos elementos mais importantes, podendo corrigir deficiências, aumentar colheitas fracas ou danificadas, aumentar a velocidade de crescimento e aumentar a qualidade de crescimento, o que constitui o objetivo principal no uso de fertilizantes. ${ }^{3}$ É importante destacar que os fertilizantes foliares, devem ser produtos quelatizados ou 
complexados, pois os complexos metal-quelatos usados em fertilizantes foliares precisam ter uma ligação química suficientemente forte para protegê-los de inesperadas reações químicas que os decomponham ou modifiquem. Mas, uma vez dentro das plantas, devem liberar facilmente o íon metálico, garantindo a chegada do nutriente intacto. A necessidade de se aplicar complexos de metais nas plantas se dá pela necessidade de nutrição e do papel fundamental que cada um dos macros e micronutrientes tem no metabolismo foliar, seja como substrato (composto orgânico) ou em sistemas enzimáticos. ${ }^{4,5}$

O objetivo desse trabalho é desenvolver alguns complexos de aminoácidos com os metais cobre, manganês, zinco, cobalto e níquel para aplicação foliar e elucidar seus prováveis mecanismos de absorção pela planta.

\section{Experimental}

Síntese dos compostos de coordenação

Os correspondentes complexos com aminoácidos dos íons metálicos já citados foram obtidos em solução aquosa, a partir de misturas estequiométricas (M:L 1:2)com controle de temperatura e pH. Essa metodologia é baseada nos conceitos fundamentais de Química de Coordenação, levando-se em conta as características de cada metal e de cada ligante a ser testado, especialmente sua estabilidade. ${ }^{6}$ Foram utilizadas amostras comerciais de $L$ - ácido aspártico (ligante 1 ) e $L$-ácido glutâmico (ligante 2), do fornecedor Labysynth, como ligantes. Para os metais cobre, manganês, cobalto e níquel foram utilizadas amostras produzidas na empresa Compass Minerals América do Sul (produtos comerciais e utilizados como matéria-prima para formulações), na forma de carbonato. Para o zinco foi utilizado óxido, do fornecedor Zinc -O - India, já homologado pela empresa.

Avaliação de compatibilidade físico-química com agrotóxicos e afins, corrosão, pH de decomposição, determinação de $\mathrm{pH}$ e densidade

Considerando a aplicação destes compostos de coordenação na agricultura na forma de "calda" (mistura de substâncias em tanque sob agitação para posterior aplicação em culturas distintas) fazse necessário avaliar a compatibilidade dos compostos em meio aquoso com agrotóxicos e também a capacidade de corrosão em relação ao ferro (material comumente utilizado nos tanques de mistura e aplicação das caldas). A avaliação da estabilidade ou mudança física da estrutura do composto de coordenação desenvolvido é de suma importância, pois, uma vez que os compostos serão aplicados em calda é necessário saber em qual $\mathrm{pH}$ a estrutura de interesse perde sua estabilidade. As determinações de $\mathrm{pH}$, densidade e solubilidade foram realizadas conforme manual de métodos analíticos oficiais para fertilizantes e corretivos. ${ }^{7}$

Secagem dos compostos via spray dryer e determinação de solubilidade

Os compostos foram secos via spray dryer conforme metodologia dominadas nos laboratórios da Compass Minerals Ind. SA. ${ }^{8}$

\section{Aplicação foliar}

A aplicação foliar foi realizada conforme metodologia dominada na fazenda experimental da Compass Minerals para determinação do índice de SPAD (Soil Plant Analysis Development Análise de desenvolvimento de planta de solo $)^{9}$ ao longo dos dias. 


\section{Resultados e Discussão}

$\mathrm{O}$ aspecto das soluções obtidas e as estruturas dos ligantes e complexos são apresentados na Figura 1. Considerando a baixa solubilidade dos metais em questão, na forma de carbonato e óxido, em água, considera-se satisfatório o aspecto límpido e sem precipitados encontrados para cada uma das soluções, demonstrando que todo o carbonato/óxido foi convertido ao complexo esperado.

A)

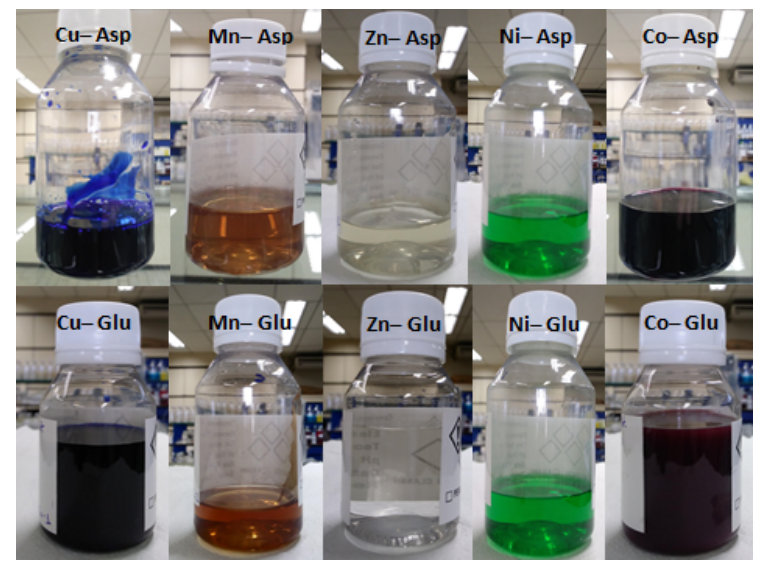

B)<smiles>NC(CC(=O)O)C(=O)O</smiles>

ác. aspártico<smiles>NC(CCC(=O)O)C(=O)O</smiles>

ác. glutâmico

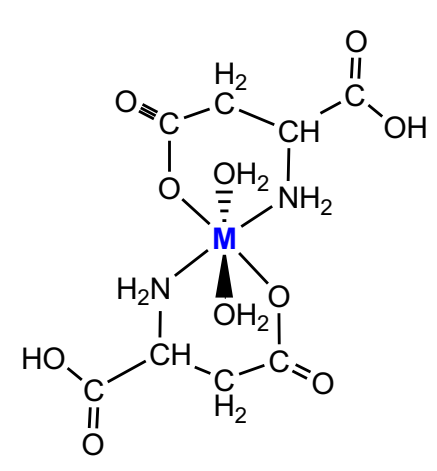

$\left[\mathrm{M}(\mathrm{asp})_{2}\left(\mathrm{H}_{2} \mathrm{O}\right)_{2}\right]$

Fig. 1 - A) Aspecto final das soluções obtidas; B) estruturas de ligantes e proposta para complexos.

A avaliação de compatibilidade físico-química com agrotóxicos foi realizada conforme ABNT NBR $13875^{10}$ utilizando como referência amostra comercial do defensivo agrícola Roundup ${ }^{\circledR}$ (glifosato) do fornecedor Monsanto. Obteve-se resultados satisfatórios evidenciando compatibilidade físico-química para todos os compostos desenvolvidos sem alteração de seu aspecto físico. Na avaliação de corrosão foi utilizada palha de aço comercial da marca Bombril®. A palha de aço foi submersa em solução aquosa de cada um dos compostos e retirada para avaliação em de aspecto físico após tempos pré-determinados. Os resultados encontrados foram satisfatórios. Para a determinação de $\mathrm{pH}$ de decomposição, a $50 \mathrm{~mL}$ de solução obtida de cada um dos compostos foram adicionadas, lentamente e em paralelo, pequenas quantidades de um ácido forte ( $\mathrm{HCl} \mathrm{37 \% )}$ ou base forte $(\mathrm{NaOH} 50 \%)$, monitorando-se o $\mathrm{pH}$ afim de determinar em qual $\mathrm{pH}$ a estrutura sofre alguma alteração. Valores de $\mathrm{pH}$ e densidade foram determinados conforme metodologia oficial. ${ }^{7}$ Os resultados estão descritos na Tabela 1.

\begin{tabular}{ccccccc}
\hline Compostos & Compatibilidade & Corrosão & $\begin{array}{c}\text { pH de quebra } \\
\text { meio ácido }\end{array}$ & $\begin{array}{c}\text { pH de quebra } \\
\text { meio básico }\end{array}$ & pH & Densidade \\
\hline Cu-Asp & Compatível & Não há & 0,2 & 11,3 & 7,5 & $0,850 \mathrm{~g} / \mathrm{cm}^{3}$ \\
Mn-Asp & Compatível & Não há & 0,2 & 12,0 & 8,0 & $0,750 \mathrm{~g} / \mathrm{cm}^{3}$ \\
Zn-Asp & Compatível & Não há & 0,2 & 11,8 & 7,5 & $0,940 \mathrm{~g} / \mathrm{cm}^{3}$ \\
Ni-Asp & Compatível & Não há & 0,2 & 12,0 & 7,5 & $0,850 \mathrm{~g} / \mathrm{cm}^{3}$ \\
Co-Asp & Compatível & Não há & 0,2 & 11,4 & 8,0 & $0,850 \mathrm{~g} / \mathrm{cm}^{3}$ \\
Cu-Glu & Compatível & Não há & 0,2 & 11,9 & 7,5 & $0,950 \mathrm{~g} / \mathrm{cm}^{3}$ \\
Mn-Glu & Compatível & Não há & 0,3 & 12,2 & 8,0 & $0,740 \mathrm{~g} / \mathrm{cm}^{3}$ \\
Zn-Glu & Compatível & Não há & 0,2 & 11,86 & 7,5 & $0,950 \mathrm{~g} / \mathrm{cm}^{3}$ \\
Ni- Glu & Compatível & Não há & 0,1 & 11,60 & 7,5 & $0,850 \mathrm{~g} / \mathrm{cm}^{3}$ \\
Co-Glu & Compatível & Não há & 0,2 & 11,1 & 8,0 & $0,810 \mathrm{~g} / \mathrm{cm}^{3}$ \\
\hline
\end{tabular}


Tabela 1 - Resultados de compatibilidade físico-química, corrosão e pH de decomposição obtidos.

Após secagem das soluções via spray dryer os compostos demonstraram propriedades higroscópicas. $\mathrm{O}$ aspecto, bem como a solubilidade desses compostos estão descritos na Figura 2.

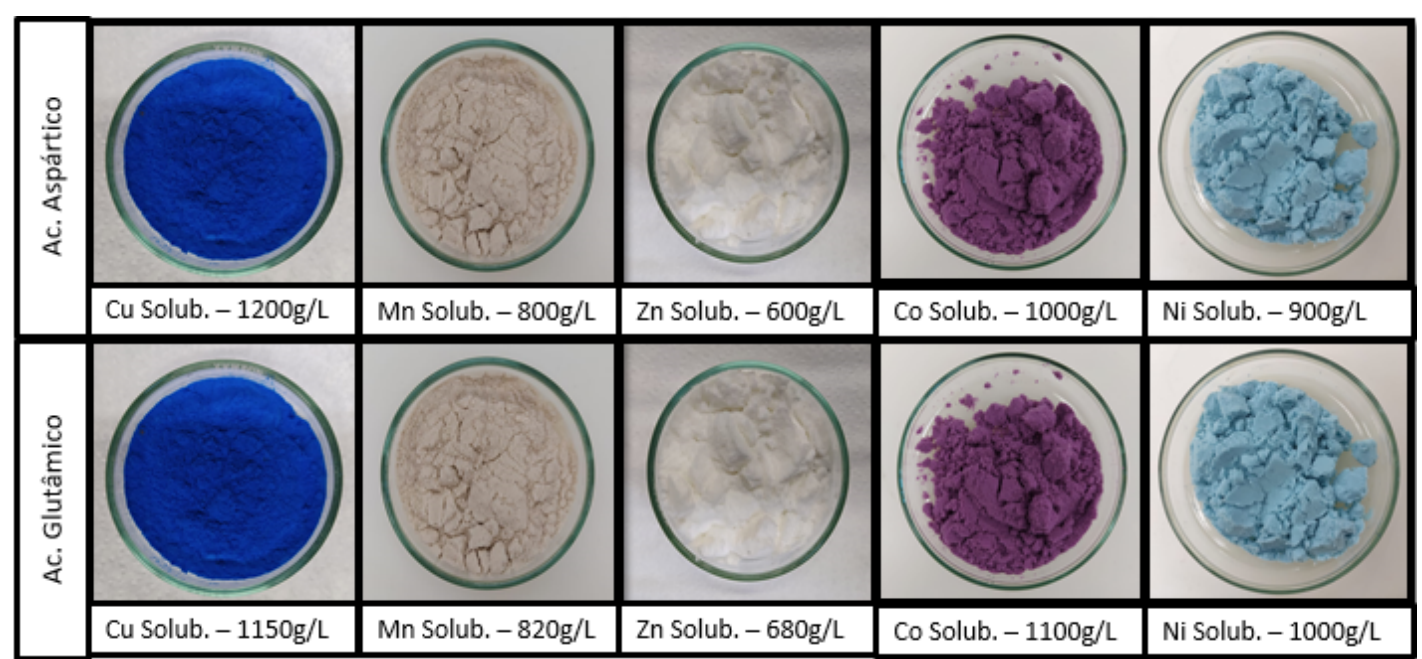

Fig. 2 - Aspecto dos compostos secos e correspondente solubilidade.

A determinação de SPAD foi realizada ao longo de dez dias, com monitoramento periódico. Os resultados, apresentados no Gráfico 1 e Figura 3, mostram que as plantas nutridas com os compostos desenvolvidos a base de ácido aspártico e ácido glutâmico com o metal manganês apresentam maior desenvolvimento do que o controle e outras fontes convencionais (como os sais carbonato, cloreto, sulfato).

\section{SPAD}

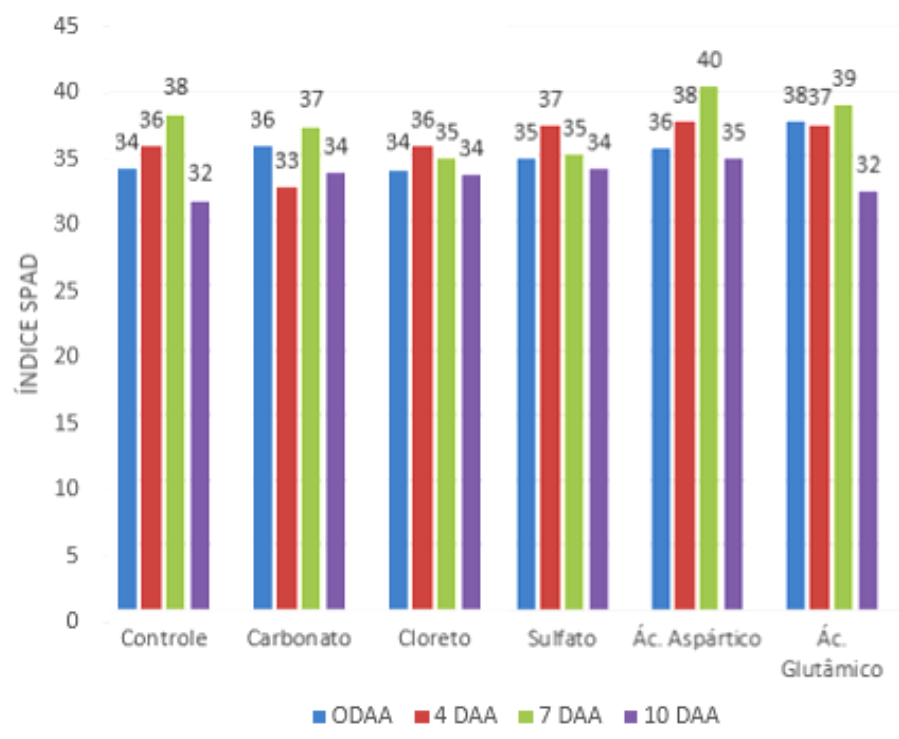

Gráfico 1 - Determinação de SPAD ao longo do tempo em plantas nutridas com os sais e complexos de manganês 


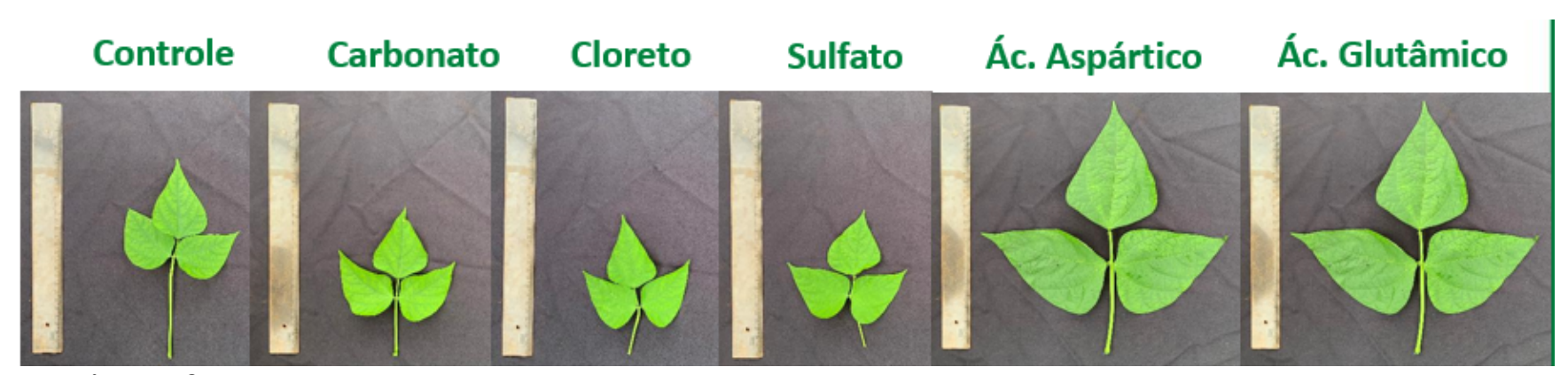

Figura 3 - Determinação de SPAD ao longo do tempo - desenvolvimento no tamanho folhas (Dados referentes aos compostos de manganês.

\section{Conclusões}

Os compostos de coordenação desenvolvidos apresentaram boa estabilidade química, compatibilidade com defensivos agrícolas e boa resposta às caracterizações diversas. Além disso, a aplicação foliar dos compostos desenvolvidos mostraram resultados promissores quanto à produtividade e reconhecimento dos ligantes pela planta, provavelmente por se tratar de compostos endógenos, isto é, ligantes orgânicos que estão presentes nas suas vias metabólicas.

\section{Agradecimentos}

Agradecemos à empresa Compass Minerals América do Sul e à Fundação de Amparo à Pesquisa do Estado de São Paulo (FAPESP, Proc. 2013/07937-8, CEPID Redoxoma) pelo apoio ao Laboratório de Bioinorgânica, Catálise e Farmacologia (IQ/USP).

\section{Referências:}

1. Reetz, H. F. Fertilizantes e o seu uso eficiente, São Paulo, Brasil, 2017.

2. Prado, R. M. Tese de Doutorado, Universidade Federal de Barretos, Brasil, 2012.

3. a) Mocellin, R. S. P. Princípios da adubação foliar- Ômega Fertilizantes, Canoas, Brasil, 2004; b) Souri, M.K., Aminochelate fertilizers: the new approach to the old problem; a review, Open Agriculture, 2016, 1, 118.

4. Yang, G. et al., Amino Acid Transporters in Plant Cells: A Brief Review, Plants, 2020, 9, 967; doi:10.3390/plants9080967.

5. Lucena, J. J. Revista Ceres 2009, 20, 527.

6. a) Martell, A. E.; Smith, R. M., Critical Stability Constants, 2nd ed, Plenum Press: New York, 1989; b) S. H. Laurie, in Handbook of Metal-Ligand Interactions in Biological Fluids: Bioinorganic Chemistry, ed. G. Berthon, Marcel Dekker, New York, 1995, vol. 1, pp. 603-619.

7. Brasil. Ministério da Agricultura, Pecuária e Abastecimento, 2014

8. Souza, V. F. D. E. A. Embrapa Informação Tecnológica. Brasília, DF, 2011.

9. Gil, P.T.; et al.; Horticultura Brasileira 2002, 20, 611-615.

10. ABNT NBR 13875, Agrotóxicos e afins - Avaliação de compatibilidade físico-química.

11. Novais, R. F; et al.; Fertilidade do Solo. $1^{\text {st }}$ ed. Sociedade Brasileira de Ciência do Solo: Viçosa, 2007.

12. Camargo, M. S. Revista Pesquisa e Tecnologia, 2012, 9.

13. Dias, J. S. Revista Unifertil, 2012, 1, 1-10. 